\title{
Optimization of Healthcare Supply Chain in Context of Macro-Ergonomics Factors by a Unique Mathematical Programming Approach
}

\author{
A. Azadeh ${ }^{\mathrm{a}, 1}$, S. Motevali Haghighi ${ }^{\mathrm{a}}{ }^{\mathrm{b}}$, Z. Gaeini ${ }^{\mathrm{a}}$, N. Shabanpour ${ }^{\mathrm{c}}$ \\ a School of Industrial and Systems Engineering, Center of Excellence for Intelligent-Based Experimental \\ Mechanic, and Department of Engineering Optimization Research, \\ College of Engineering, University of Tehran, Iran \\ ${ }^{\mathrm{b}}$ Department of Industrial Engineering, Esfarayen University of Technology, Esfarayen, 9661998195, Iran \\ ${ }^{c}$ Department of Mechanical Engineering, Polytechnic University of Milan, Milan, Italy
}

\begin{abstract}
This study presents an integrated approach for analyzing the impact of macro-ergonomics factors in healthcare supply chain (HCSC) by data envelopment analysis (DEA). The case of this study is the supply chain (SC) of a real hospital. Thus, healthcare standards and macro-ergonomics factors are considered to be modeled by the mathematical programming approach. Over 28 subsidiary SC divisions with parallel missions and objectives are evaluated by analyzing inputs and outputs through DEA. Each division in this HCSC is considered as decision making unit (DMU). This approach can analyze the impact of macro-ergonomics factors on supply chain management (SCM) in healthcare sector. Also, this method ranks the relevant performance efficiencies of each HCSC. In this study by using proposed method, the most effective macro-ergonomics factor on HCSC is identified as "teamwork" issue. Also, this study would help managers to identify the areas of weaknesses in their SCM system and set improvement target plan for the related SCM system in healthcare industry. To the best of our knowledge, this is the first study for macro-ergonomics optimization of HCSC.
\end{abstract}

Keywords: Human Factors; Healthcare Supply Chain (HCSC); Data Envelopment Analysis (DEA); Macro- Ergonomics; Sensitivity Analysis

\footnotetext{
${ }^{1}$ Corresponding author: Tel: +98 2188021067; Fax: +98 2182084194.

E-mail address: aazadeh@ut.ac.ir
} 


\section{Introduction}

A supply chain (SC) is a value chain network in every industrial system. In healthcare industries, SCs are the most costly part of system. Thus, evaluating of management in healthcare supply chain (HCSC) is evident (McKone-Sweet et al., 2005). Human factors play an important role in SCM (Kim, 2005). This paper analyzes the impact of macro-ergonomics factors on HCSC. The basic theory in this matter is focusing on the role of human factors and managerial decisions in a real hospital in Tehran, Iran.

Regarding SCM in healthcare sector, Kelle et al. (2012) and Narayana et al. (2014) proposed an approach to improve the current management of the pharmacy SC. Bendavid and Boeck (2011) studied SCM of a hospital to redesign the renewal process. Kim (2005) developed a pharmaceutical SCM system to optimize the costs and inventories. Also, McGrath and More (2001) presented an integrated approach to improve HCSC efficiency. Although dealing with complexity in the SC is difficult, a large number of studies support this complexity to achieve the better performances (Bozarth et al., 2009; Koudal and Engel, 2007; Perona and Miragliotta, 2004; Vachon and Klassen, 2002; Van der Vorst and Beulens, 2002; Behzad et al., 2011).

Time and cost play an important role in performance of the hospital and the importance of these factors on healthcare performance are expressed by some researchers such as Cheng and Whittemore (2008), Haszlinna Mustaffa and Potter (2009), and Kehrel (2014).

There are several studies on performance of the healthcare issue. In this regards, an improvement approach for HCSC is presented by Rossetti (2008). Kim et al. (2013) and Konrad et al. (2013) applied simulation method to model performance of healthcare system. Wang et al. (2014) and Lowndes and Susan (2014) evaluated healthcare systems to improve safety. 
The role of human elements in complex systems is inevitable (Paillé and Boiral, 2013; Clegg, 2000; Serdarasan, 2011) and there is lack of study with respect to human factors issues. In this regard, Khan et al. (2013) presented an integrated mathematical model considering human errors. Barnes and Liao (2012) studied the effect of individuals and network in SCM by considering human resource management. Other studies considered human resources and aspects of SC (Fung and Chen, 2010; Koulikoff-Souviron and Harrison, 2006; Harrison, 1999).

Improvement of SCM performance is the aim of many industries (Khan et al. 2013). Healthcare industries are one of the most important sectors in every society. SC costs are the greatest part of healthcare industries (McKone-Sweet et al., 2005) and the effect of humans in this matter is indispensable. In this case, Sinclair and Siemieniuch (1995) discussed certain ergonomics issues involved in simultaneous engineering from the perspective of SCs.

Siemieniuch (2000) classified different sectors of SCM to several roles such as supervisor, inspection, project management, suppliers, finance management, security, marketing, costumers and purchasing. The SCM can be defined as a social network. Workers and decision makers in this network are human elements that are connected with technology and played a significant role in the development of the system (Paella et al., 2013). People work better when they have comprehensive understanding of their works (Davis, 1982). Moreover, they are the set of characteristics which Ulich (1989) mentioned as concepts of humanization of work.

It is clear that, healthcare industry has a key role in human health and quick access to the medicine is one of the important issues that has the significant impact on healthcare department. It is therefore quite essential to evaluate medicine SC to enhance performance of the healthcare department. Hence, medicine SC of a real hospital is evaluated by incorporating ergonomics and macro-ergonomics factors, cost and time of delivering medicine to customers. Based on experts' opinions, aforementioned factors play a vital role in medicine availability, system 
reliability, and delivery time and cost. Therefore, considering the ergonomics and macro ergonomics factors for evaluation medicine SC performance is justified.

This study proposes a method for analyzing the impact of macro-ergonomics factors in HCSC systems. It demonstrates how data envelopment analysis (DEA) enables a hospital to simultaneously analyze multiple output/input indicators to precisely determine performance and also identify the most effective macro-ergonomics factors. In this regard, 28 units in a SC of a hospital are took into account as decision making units (DMUs). Cost and time of delivering medicine to customers are considered as inputs whilst human factors about SCM in healthcare issue are proposed as outputs. The system of delivering medicine from main factory or depot to the hospital's patients is considered as SC system. After data gathering through questionnaire, DEA approach is presented with respect to the set of comprehensive ergonomics factors obtained in previous steps in order to rank all units of SC to find the best one. Moreover, sensitivity analysis is performed to identify the most important factors. Finally, management decisions are derived from ergonomics viewpoint to improve the performance of SC in this particular case study.

\subsection{Motivation and Significance}

Healthcare industry has significant role in growth of national economy and health. In addition, medicine SC is one of the most costly divisions of healthcare. Given the costly nature of these issues, the management system could play an important role to reduce the costs and delivery time and increase medicine availability and system reliability. Furthermore, the impact of traditional ergonomics in addition to macro-ergonomics factors in a HCSC becomes quite considerable and important. Moreover, both human and organizational elements can cause errors and reduction of efficiencies in HCSC and the reliable and available system can be achieved by incorporating ergonomics and macro-ergonomics factors. This study for the first time presents concurrent evaluation and optimization of micro- and macro-ergonomics 
factors in healthcare SCM. Moreover, previous studies have not considered the human, organizational, and technological issues of HCSC. The results of this study would applied total human factors issues in context of healthcare SCM.

This study is organized as follows: Section 2 presents the methodology which is used in this study. Section 3 shows the application of the approach on real case study. Analysis and discussion are presented in Section 4. Concluding remarks are provided in Section 5.

\section{Methodology}

Effective and operative performance in healthcare organizations is really important because of the nature of healthcare industries. One of the important part of these industries is medicine SC. Proper performance of the aforementioned SC has a direct impact on the performance of the entire healthcare organizations. In this regard, a mathematical model is provided to assess the medicine SC of a real hospital in Iran. DEA as mathematical model is utilized in this study to calculate efficiencies and rank DMUs. Hereupon, the proper inputs and outputs must be selected as key performance indicators (KPIs). To do this, ergonomics and macro-ergonomics are chosen as KPIs because of the importance of these KPIs on medicine SC performance. The data required is gathering through standard questionnaire.

As stated before, 28 units of medicine SC are taken into account as DMUs. Cost and time of delivering medicine to customers are considered as inputs and human factors about SCM in healthcare issue are proposed as outputs. The system of delivering medicine from main factory or depot to the hospital's patients is considered as SC system. Then, by utilized DEA method, efficiency scores are calculated considering macro-ergonomics and ergonomics criteria. This efficiency score demonstrates the performance of the each unit from ergonomics viewpoint. The unit that has the highest efficiency score can be selected as the best unit in terms of ergonomic issues. In addition, by applying sensitivity analysis, the most important shaping 
factors are identified to help decision makers in futures decisions and enhancing the performance of hospital.

Figure 1 depicts the overall approach of this study for performance assessment of SCM systems and analyzing impact of macro-ergonomics on system, and it includes 9 main steps as follows:

\section{Step 1. Questionnaire design}

In order to gather necessary data, managers and experts of different units in medicine SC answered to 27 questions of questionnaire related to human factors. Cost and time of delivering medicine to customers are quantitative factors which are collected from historical data. But, the other factors are qualitative which has been gathered by questionnaire. Respondents must assign a number between 1 and 10 to each question ( 1 means very low, 10 means very high). Appendix I shows the related questionnaire for this study.

\section{Step 2. Reliability test on questionnaire}

The data gathered from the questionnaires is analyzed through reliability test by SPSS ${ }^{\circledR}$ Reliability is assessed via Cronbach's alpha. The value of Cronbach's alpha is $63 \%$ by considering 27 questions that this value can be acceptable for this case.

\section{Step 3. Integration and identification of SCM system}

In this study, two kinds of medicine SC from factory or depot to the drugstore of the hospital are considered. The SC system of two different kinds of medicine are evaluated through the proposed approach. The SCM system has several sectors which effect on efficiencies values. 28 sectors are selected in this SCM system according to Siemieniuch (2000) study on healthcare SCM and experts' opinions.

\section{Step 4. Determination of inputs and outputs}

Cost and time of delivering medicine to customers are considered as inputs and human factors about SCM in healthcare issue are proposed as outputs. Human factors are categorized 
into two criteria, namely, micro-ergonomics and macro-ergonomics. Mental power, physical strength, knowledge about situation assessment and situation analysis, business specifications and equipment, information and communication in system, human resource management culture, teamwork and effective communication are selected as outputs.

\section{Step 5. Choose proper DEA model}

In this study, DEA is used for efficiency evaluation of HCSC. DEA approach is applied to optimize the performance of medicine SC. To do this, an output-oriented DEA model with a variable returns to scale (VRS) frontier type is used because the percentage change in output values are not a function of direct change in input values (Azadeh et al., 2104).

\section{Steps 6. Apply DEA model and calculating efficiencies}

In this step, DEA must be implemented to calculate efficiency scores for each DMU. The most efficient DMU is identified in this step.

\section{Step 7. Sensitivity analysis}

Sensitivity analysis is performed to identify the most important shaping factors. To do this, DEA model is applied for all macro-ergonomics and ergonomics factors, separately. If the macro-ergonomics factors are more important than ergonomics, run DEA model five times for each macro-ergonomics factor, separately and vice versa. Finally the most influential factors are identified based on the greatest change creation in the efficiency score.

\section{Step 8. Calculating potential for improvement}

In this step the calculated values of efficiencies are compared to each other. In addition, the effect of ergonomics and macro-ergonomics criteria are recognized, separately.

Also, in this step by using of average value of measured data and average value of calculated target value from solving DEA model, the average potential for improving the SCM system is calculated. These potential values used to improve and optimize system's situations in point of view of human factors. 


\section{Step 9. Auditing and Monitoring DEA Results}

In this step auditing and monitoring should have been applied that can help managers to improve and optimize their SCM system by considering human factors criteria. 


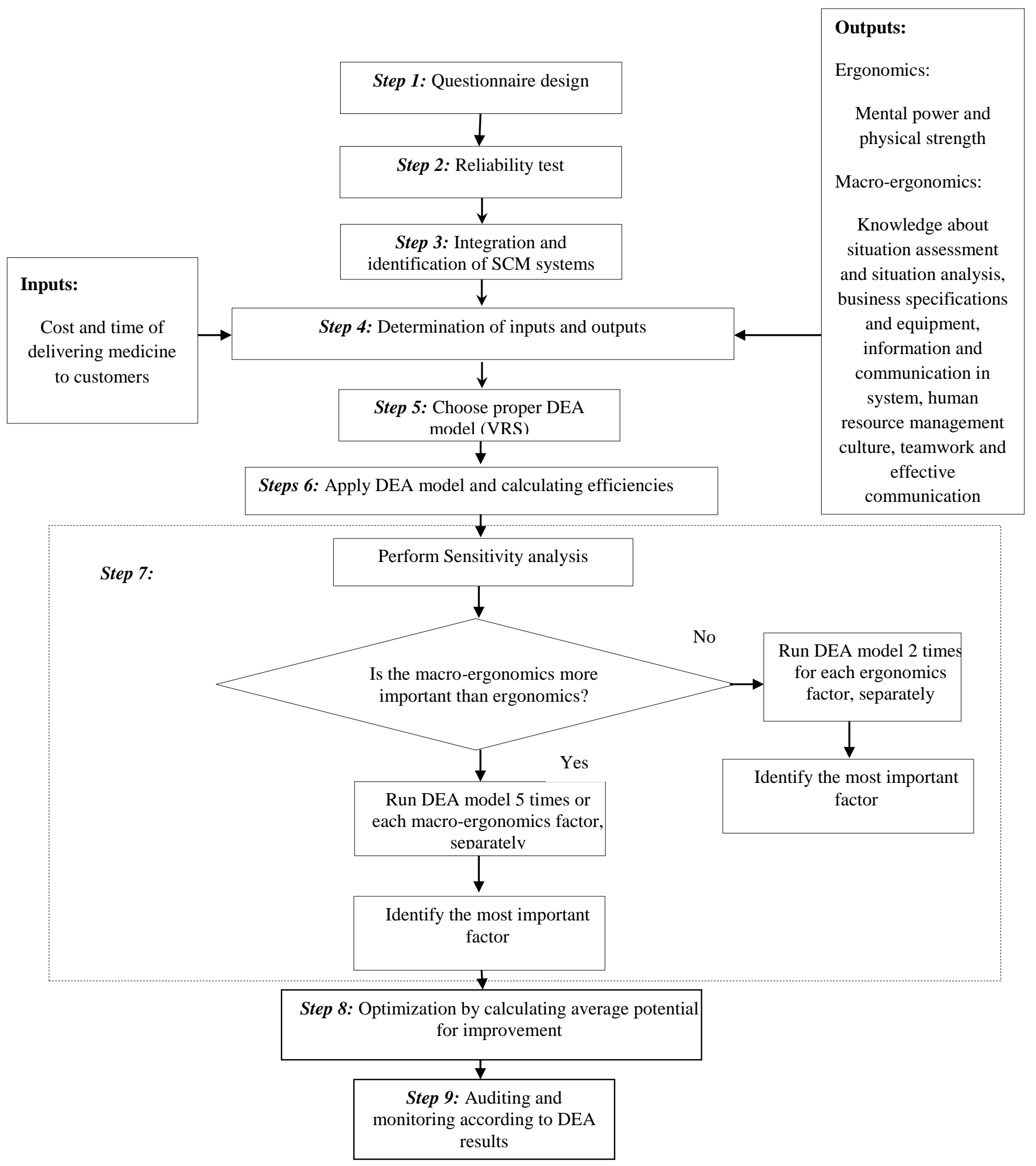

Figure 1: Schematic view of proposed approach for this study 


\subsection{Data Envelopment Analysis (DEA)}

DEA model is a non-parametric approach to evaluate performance of different DMUs that has been introduced by Charnes et al. (1978) and Banker et al. (1984). The advantages of this approach are clearly understood. This approach is a powerful decision support tool for calculating efficiency that has the appropriate performance than the other assessment tools (Azadeh et al., 2013; Azadeh et al., 2016). This method has been used in several researches as an evaluator and analyzer tool. Super efficiency models are used to define critical outputs in several researches (Lovell and Rouse, 2003). Furthermore, there are some researches that used DEA method in healthcare context (Jacob, 2001; Salinas et al., 1996; Parkin et al., 1997). Also, this method has been used in context of macro-ergonomics to analyze efficiency of sectors (Azadeh et al., 2012). Efficient and inefficient units can be identified by utilizing DEA in order to help decision makers for continuous performance assessment and improvement of their systems. DEA models can handle complex system with multiple inputs and outputs to compute efficiency score for each DMU. DEA is a widely used approach to assess healthcare performance (Azadeh et al., 2013; Azadeh et al., 2016). Based on mathematical model, Model (1), the frontier generated by this method is a surface that follows the most efficient performers (Charnes et al., 1978). This frontier demonstrates the maximum combination of outputs obtained from a given level of inputs. It is clear that determining mathematical relationships between input and output indicators is difficult. Hence, the empirical frontier is applied by considering all the relatively efficient DMUs in order to overcome to this problematical issue and the efficient DMUs are placed on this frontier. Given these characteristics, this model is chosen to evaluate medicine SC for this particular case study. To do this, an output-oriented DEA model with a VRS frontier type is used because the percentage change in output values are not a function of direct change in input values (Azadeh et al., 2104; Banker et al., 1984). Model (1) shows the VRS model which had been introduced by Banker et al. (1984): 
$\operatorname{Max} \theta$

$$
\begin{aligned}
& \text { s.t. } \quad x_{i 0} \geq \sum_{j=1}^{28} \lambda_{j} x_{i j} \quad i=1, \ldots, 2 \\
& \theta y_{r 0} \leq \sum_{j=1}^{28} \lambda_{j} y_{r j} \quad r=1, \ldots, 7 \\
& \sum_{j=1}^{28} \lambda_{j}=1 \\
& \lambda_{j} \geq 0 \quad j=1, \ldots, 28
\end{aligned}
$$

VRS model is shown in Model (1). In this model, the envelopment surface is formed as VRS. This assumption is provided by third constraint. In the above model, $x_{i j}$ shows value of ith input for jth DMU and $y_{r j}$ shows value of rth output for jth DMU. $\theta$ demonstrates efficiency score for DMU under study and $x_{i 0}$ and $y_{r 0}$ shows input and output of DMU under study respectively. Outputs must be maximized in this model so that the inputs of model to be constant. In other words, it is desirable that output be maximized by a specified amount of inputs. It means that the ergonomics and macro-ergonomics must be maximized considering a specific amount of cost and time delivery for each department in the SC under study. First and second constraint illustrate that the weighted sum of inputs cannot be upper than value of ith input for target DMU, $x_{i o}$; and the weighted sum of outputs must be greater than $\theta y_{r 0}$, respectively. As stated before, this model provides an efficient frontier demonstrated the maximum combination of outputs obtained from a given level of inputs and the efficient DMUs are placed on this frontier. Each department in medicine SC is considered as DMU, so the efficiency score of efficient department is equal to 1 (Charnes et al., 1978; Banker et al., 1984). The efficient department has the best performance with respect to ergonomics and macroergonomics factors and specific cost and time. Therefore, efficient an inefficient DMUs are identified through this approach. To achieve the full ranking of DMUs, Model (2) introduced by Jahanshahloo et al. (2005) is used for DEA based ranking purposes. In the Model (2), $s_{i}^{-}$and 
$s^{+}{ }_{r}$ are the slack variables. It should be noted that the distance between each DMU's indicator and the efficient frontier is called slack. Decision makers provide improvement solutions to alleviate these slacks in order to reach the efficient frontier. Figure 2 shows the empirical frontier created by DEA approach.

$\operatorname{Max} \theta-\varepsilon\left(\sum_{i=1}^{2} s_{i}^{-}+\sum_{r=1}^{7} s_{r}^{+}\right)$

s.t.

$\sum_{\substack{j=1 \\ j \neq 0}}^{28} \lambda_{j} x_{i j}+s_{i}^{-}=x_{i 0} \quad \forall i=1,2$

$\sum_{\substack{j=1 \\ j \neq 0}}^{28} \lambda_{j} y_{r j}-s_{r}^{+}=\theta y_{r 0} \quad \forall i=1, \ldots, 7$

$\sum_{\substack{j=1 \\ j \neq 0}}^{28} \lambda_{j}=1$

$\lambda_{j}, s_{i}^{-}, s_{r}^{+} \geq 0 \quad \forall \mathrm{j}(\mathrm{j} \neq 0)$ and $\theta$ is free

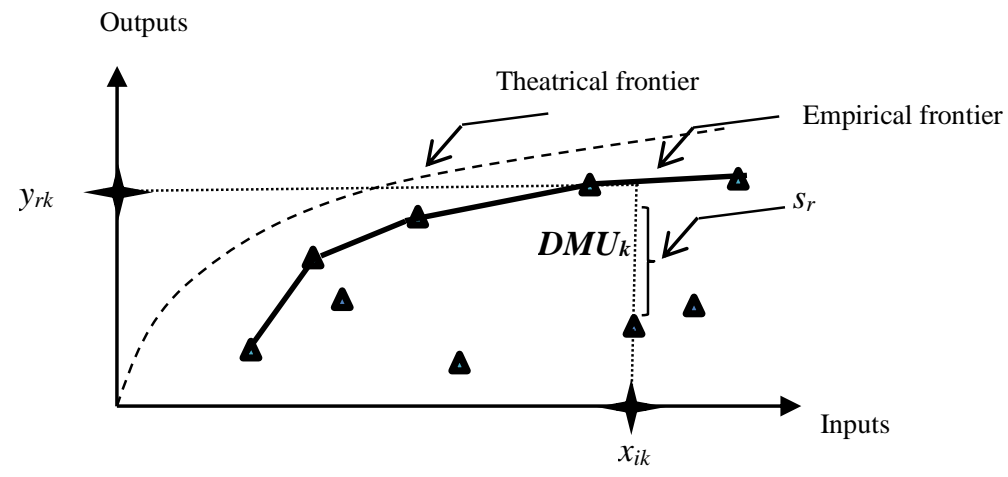

Figure 2: Empirical frontier created by DEA 


\section{Case Study: An Actual Hospital}

Healthcare is one of the extensive industry that provides goods and services to treat patients. Preparing medicines and quick access to medicines play a crucial role in hospital performance. In the hospital under investigation, every medicine is available through a particular SC. Usually, medicines are provided via two ways. There are some factories produced the medicine completely or by using some material from foreign countries and other medicines are imported into Iran directly. Hence, two kinds of drugs with two different SCs are considered. First medicine is produced in another country and imported to Iran and the second one is produced in Tehran, Iran. Medicines' SC is usually outside of the hospital and there is a long way to be reached to patients. There are some depots that medicines store in them. Imported medicine is stored in an initial depot near Tabriz, Iran and then is transported to central depot in Tehran, Iran. The second type medicines are transported to central depot directly. Then, according to hospital's demands, medicines are transported to hospital weekly. When physicians prescribe these medicines for patients, our SC is completed. Figure 3 presents a schematic view of the SC.

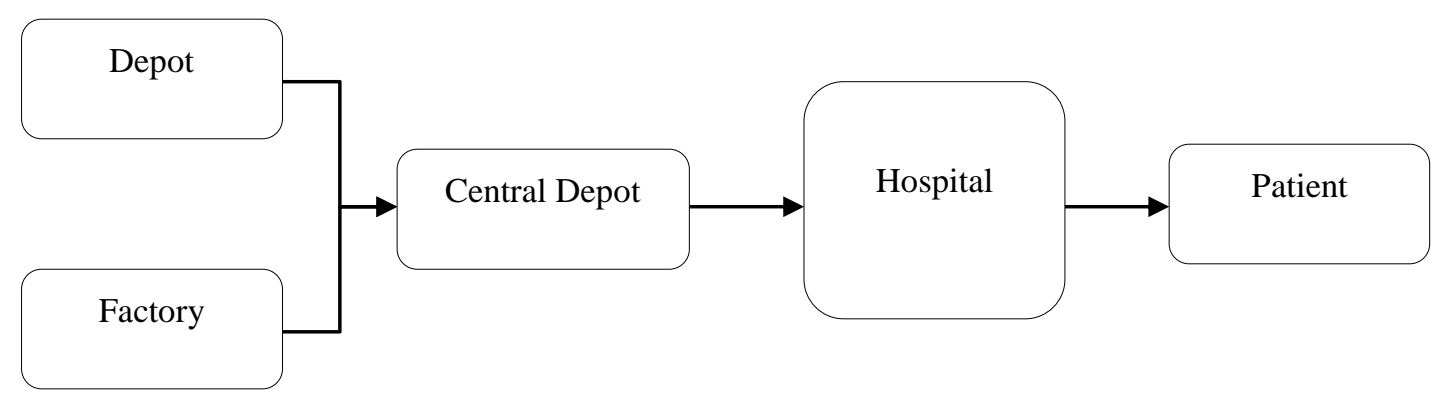

Figure 3: A multi-stage SC system

As stated before, there are 28 units or departments in the mentioned SC considered as DMUs in order to evaluate performance of the medicine SC from ergonomics viewpoint. In this SC, the departments with similar tasks are parallel such as technical-01 and technical-02 
departments whilst sequence departments perform different tasks such as technical-01 and finance-01. The managers and experts of each unit filled the required questionnaire. By considering macro-ergonomics aspects of human factors, 7 outputs and 2 inputs are defined (Ulich, 1989; Davis, 1982; Paella et al., 2013; Siemieniuch, 2000). Cost $\left(x_{1}\right)$ and time $\left(x_{2}\right)$ of delivering medicine to customers are considered as inputs and human factors about SCM in healthcare issue are proposed as outputs. Human factors are categorized to two criteria, namely, micro-ergonomics and macro-ergonomics. Mental power $\left(y_{1}\right)$, physical strength $\left(y_{2}\right)$, knowledge about situation assessment and situation analysis $\left(y_{3}\right)$, business specifications and equipment $\left(y_{4}\right)$, information and communication in system $\left(y_{5}\right)$, human resource management culture $\left(y_{6}\right)$, teamwork and effective communication $\left(y_{7}\right)$ are selected as outputs.

Moreover, these indicators are the most meaningful outputs and inputs for this actual case. This has been verified and validated through various interviews with managers of this hospital. To do this, the significance of these indicators on the medicine SC performance is confirmed by experts through oral interviews. They believed ergonomics and macro-ergonomics factors play a vital role in medicine availability, system reliability, and delivery time and cost. Therefore, considering the ergonomics and macro ergonomics factors for evaluation medicine SC performance is justified.

\subsection{Data Gathering}

The managers and experts of each sector of medicine SC constitute the statistical population of this study. Then, standard questionnaires with respect to ergonomics and macro-ergonomics factors are completed by managers and experts. The definitions of DMUs in this study are presented in Table 1. Table 2 shows value of each indicator obtained through questionnaire and historical data.

Table 1. DMUs in SCM

\begin{tabular}{cccc}
\hline DMU & SCM Section & DMU & SCM Section \\
\hline DMU $_{1}$ & Costumer-01 & DMU $_{15}$ & Transportation-01 \\
DMU $_{2}$ & Project management-01 & DMU $_{16}$ & Process Engineer-03 \\
DMU $_{3}$ & Project management-02 & DMU $_{17}$ & Transportation-02
\end{tabular}


Table 1. DMUs in SCM

\begin{tabular}{cccc}
\hline DMU & SCM Section & DMU & SCM Section \\
\hline DMU $_{4}$ & Marketing-01 & DMU $_{18}$ & Marketing-03 \\
DMU $_{5}$ & Marketing-02 & DMU $_{19}$ & Supplier-04 \\
DMU $_{6}$ & Process Engineer-01 & DMU $_{20}$ & Transportation-02 \\
DMU $_{7}$ & Project management-03 & DMU $_{21}$ & Supplier-05 \\
DMU $_{8}$ & Process Engineer-02 & DMU $_{22}$ & Tecnical-01 \\
DMU $_{9}$ & Costumer-02 & DMU $_{23}$ & Purchasing-01 \\
DMU $_{10}$ & Supplier-01 & DMU $_{24}$ & Technical-01 \\
DMU $_{11}$ & Supplier-02 & DMU $_{25}$ & Technical-02 \\
DMU $_{12}$ & Finance-01 & DMU $_{26}$ & Technical-03 \\
DMU $_{13}$ & Purchasing-01 & DMU $_{27}$ & Finance-01 \\
DMU $_{14}$ & Supplier-03 & DMU $_{28}$ & Finance-01 \\
\hline
\end{tabular}

Table 2: Input and output values for the all of DMUs

\begin{tabular}{|c|c|c|c|c|c|c|c|c|c|}
\hline \multirow{2}{*}{ Unit } & \multicolumn{2}{|c|}{ Input } & \multicolumn{7}{|c|}{ Output } \\
\hline & $x_{1}$ & $x_{2}$ & $y_{1}$ & $y_{2}$ & $y_{3}$ & $y_{4}$ & $y_{5}$ & $y_{6}$ & $y_{7}$ \\
\hline $\mathrm{DMU}_{1}$ & 32.61 & 0.38 & 9.57 & 10.00 & 6.50 & 8.00 & 8.60 & 9.33 & 9.45 \\
\hline $\mathrm{DMU}_{2}$ & 28.73 & 0.84 & 8.89 & 7.82 & 8.91 & 8.68 & 7.04 & 7.05 & 6.09 \\
\hline $\mathrm{DMU}_{3}$ & 14.37 & 0.41 & 9.76 & 8.40 & 9.12 & 9.65 & 8.76 & 7.96 & 9.51 \\
\hline $\mathrm{DMU}_{4}$ & 38.51 & 0.96 & 8.75 & 7.45 & 7.73 & 8.87 & 9.30 & 7.90 & 7.90 \\
\hline $\mathrm{DMU}_{5}$ & 2.00 & 0.29 & 8.03 & 7.06 & 7.04 & 8.02 & 7.32 & 6.56 & 7.43 \\
\hline $\mathrm{DMU}_{6}$ & 26.17 & 0.70 & 8.71 & 7.55 & 8.25 & 7.56 & 8.01 & 8.08 & 7.73 \\
\hline $\mathrm{DMU}_{7}$ & 11.90 & 0.80 & 9.25 & 7.50 & 7.25 & 7.33 & 8.01 & 8.67 & 8.53 \\
\hline $\mathrm{DMU}_{8}$ & 23.17 & 0.89 & 8.50 & 6.00 & 8.50 & 9.34 & 7.93 & 8.67 & 8.25 \\
\hline $\mathrm{DMU}_{9}$ & 7.04 & 0.32 & 9.20 & 8.92 & 9.29 & 9.57 & 8.40 & 9.32 & 9.25 \\
\hline $\mathrm{DMU}_{10}$ & 16.52 & 0.58 & 8.75 & 8.50 & 9.26 & 8.67 & 8.00 & 7.67 & 8.10 \\
\hline $\mathrm{DMU}_{11}$ & 8.19 & 0.27 & 8.75 & 7.00 & 8.90 & 8.34 & 6.78 & 8.00 & 7.30 \\
\hline $\mathrm{DMU}_{12}$ & 5.33 & 0.48 & 8.23 & 6.50 & 8.75 & 8.33 & 8.80 & 8.00 & 8.50 \\
\hline $\mathrm{DMU}_{13}$ & 16.04 & 0.08 & 8.80 & 8.04 & 8.30 & 8.59 & 8.60 & 7.84 & 8.40 \\
\hline $\mathrm{DMU}_{14}$ & 30.18 & 0.18 & 8.75 & 9.45 & 8.25 & 7.67 & 7.20 & 8.45 & 8.05 \\
\hline $\mathrm{DMU}_{15}$ & 38.96 & 0.47 & 8.50 & 7.00 & 8.50 & 9.20 & 7.50 & 8.33 & 7.35 \\
\hline $\mathrm{DMU}_{16}$ & 13.12 & 0.40 & 9.25 & 9.35 & 8.25 & 9.30 & 8.00 & 9.67 & 8.70 \\
\hline $\mathrm{DMU}_{17}$ & 25.96 & 0.95 & 9.25 & 6.50 & 8.25 & 8.33 & 8.60 & 8.67 & 7.80 \\
\hline $\mathrm{DMU}_{18}$ & 32.07 & 0.06 & 8.50 & 7.00 & 8.25 & 8.33 & 8.42 & 8.67 & 7.60 \\
\hline $\mathrm{DMU}_{19}$ & 24.88 & 0.56 & 8.75 & 9.60 & 8.25 & 8.94 & 8.32 & 8.50 & 7.90 \\
\hline $\mathrm{DMU}_{20}$ & 8.56 & 0.36 & 8.89 & 7.12 & 8.39 & 8.44 & 8.23 & 8.18 & 8.30 \\
\hline $\mathrm{DMU}_{21}$ & 33.41 & 0.58 & 8.33 & 7.83 & 6.28 & 8.98 & 6.78 & 8.38 & 6.78 \\
\hline $\mathrm{DMU}_{22}$ & 29.96 & 0.88 & 8.45 & 9.03 & 9.49 & 9.04 & 6.77 & 9.34 & 6.99 \\
\hline $\mathrm{DMU}_{23}$ & 4.83 & 0.09 & 8.49 & 6.23 & 6.03 & 8.43 & 7.83 & 8.00 & 7.75 \\
\hline $\mathrm{DMU}_{24}$ & 6.97 & 0.04 & 7.60 & 9.02 & 8.47 & 7.92 & 7.93 & 8.85 & 7.40 \\
\hline $\mathrm{DMU}_{25}$ & 7.13 & 0.45 & 6.98 & 8.74 & 9.37 & 7.55 & 7.98 & 9.74 & 7.99 \\
\hline $\mathrm{DMU}_{26}$ & 15.07 & 0.64 & 7.62 & 9.80 & 9.91 & 9.77 & 9.10 & 8.86 & 8.94 \\
\hline $\mathrm{DMU}_{27}$ & 19.08 & 0.83 & 9.82 & 7.24 & 7.32 & 7.72 & 7.76 & 7.79 & 9.28 \\
\hline $\mathrm{DMU}_{28}$ & 5.13 & 0.04 & 9.66 & 9.21 & 9.98 & 9.01 & 7.98 & 9.03 & 8.32 \\
\hline Average & 18.78 & 0.48 & 8.72 & 8.00 & 8.31 & 8.56 & 8.00 & 8.41 & 8.06 \\
\hline
\end{tabular}




\subsection{DEA Results}

DEA model, (Model (1)), is solved by using Auto Assess software (Azadeh et al., 2007). The measured values of technical efficiencies are shown in Table 3 , as declared before, the technical efficiencies demonstrates the degree of performance of each DMU with respect to mentioned KIPs. According to obtained values, technical efficiencies is equal to 1 for 14 DMUs. Therefore, ranking of DMUs by using these values is impossible. For full ranking, Model (2) is applied (Jahanshahloo et al., 2005). The efficiency score and associated rank for each DMU are shown in Table 4.

Table 3: Technical efficiency for each DMU

\begin{tabular}{lclc}
\hline DMU & Technical efficiency & DMU & Technical efficiency \\
\hline DMU $_{1}$ & 1 & DMU $_{15}$ & 0.92 \\
DMU $_{2}$ & 0.929 & DMU $_{16}$ & 1 \\
DMU $_{3}$ & 1 & DMU $_{17}$ & 0.99 \\
DMU $_{4}$ & 1 & DMU $_{18}$ & 1 \\
DMU $_{5}$ & 1 & DMU $_{19}$ & 0.925 \\
DMU $_{6}$ & 0.928 & DMU $_{20}$ & 0.919 \\
MMU $_{7}$ & 0.925 & DMU $_{21}$ & 0.933 \\
MMU $_{8}$ & 0.968 & DMU $_{22}$ & 1 \\
DMU $_{9}$ & 1 & DMU $_{23}$ & 0.925 \\
DMU $_{10}$ & 0.949 & DMU $_{24}$ & 0.915 \\
DMU $_{11}$ & 0.909 & DMU $_{25}$ & 1 \\
DMU $_{12}$ & 1 & DMU $_{26}$ & 1 \\
MMU $_{13}$ & 1 & MMU $_{27}$ & 1 \\
DMU $_{14}$ & 0.925 & MMU $_{28}$ & 1 \\
\hline
\end{tabular}

Table 4: Complete ranking for each DMU

\begin{tabular}{cccccc}
\hline Rank & Efficiency & $\mathrm{j}\left(\mathrm{DMU}_{\mathrm{j}}\right)$ & Rank & Efficiency & $\mathrm{j}\left(\mathrm{DMU}_{\mathrm{j}}\right)$ \\
\hline 1 & 1 & 5 & 15 & 0.791 & 26 \\
2 & 1 & 24 & 16 & 0.761 & 10 \\
3 & 1 & 28 & 17 & 0.73 & 14 \\
4 & 0.957 & 23 & 18 & 0.724 & 27 \\
5 & 0.904 & 18 & 19 & 0.697 & 19 \\
6 & 0.908 & 9 & 20 & 0.684 & 8 \\
7 & 0.986 & 12 & 21 & 0.679 & 6 \\
8 & 0.976 & 25 & 22 & 0.672 & 1 \\
9 & 0.939 & 13 & 23 & 0.668 & 17 \\
10 & 0.935 & 4 & 24 & 0.656 & 22 \\
11 & 0.979 & 20 & 25 & 0.654 & 2 \\
12 & 0.866 & 16 & 26 & 0.651 & 15 \\
13 & 0.841 & 3 & 27 & 0.636 & 11 \\
14 & 0.812 & 7 & 28 & 0.633 & \\
\hline
\end{tabular}


As mentioned before, the distance between each DMU's indicator and the efficient frontier is called slack. Decision makers provide improvement solutions to alleviate these slacks in order to reach the efficient frontier. Table 5 shows these slacks for each DMU's indicator and the values of efficient input and output targets are presented in Table 6 according to slack values and input and output values demonstrated in Tables 2 and 5 respectively.

Table 5: Slack values for each DMU

\begin{tabular}{|c|c|c|c|c|c|c|c|c|c|}
\hline \multirow{2}{*}{ Unit } & \multicolumn{2}{|c|}{ Input } & \multicolumn{7}{|c|}{ Output } \\
\hline & $s_{1}$ & $s_{2}$ & $s_{1}$ & $s_{2}$ & $s_{3}$ & $S_{4}$ & $s_{5}$ & $s_{6}$ & $s_{7}$ \\
\hline $\mathrm{DMU}_{1}$ & 0.000 & 0.000 & 0.000 & 0.000 & 0.000 & 0.000 & 0.000 & 0.000 & 0.000 \\
\hline $\mathrm{DMU}_{2}$ & 18.83 & 0.596 & 0.000 & 0.469 & 0.000 & 0.000 & 0.820 & 0.951 & 2.334 \\
\hline $\mathrm{DMU}_{3}$ & 0.000 & 0.000 & 0.000 & 0.000 & 0.000 & 0.000 & 0.000 & 0.000 & 0.000 \\
\hline $\mathrm{DMU}_{4}$ & 0.000 & 0.000 & 0.000 & 0.000 & 0.000 & 0.000 & 0.000 & 0.000 & 0.000 \\
\hline $\mathrm{DMU}_{5}$ & 0.000 & 0.000 & 0.000 & 0.000 & 0.000 & 0.000 & 0.000 & 0.000 & 0.000 \\
\hline $\mathrm{DMU}_{6}$ & 12.00 & 0.311 & 0.000 & 0.769 & 0.000 & 1.265 & 0.000 & 0.000 & 1.041 \\
\hline $\mathrm{DMU}_{7}$ & 0.000 & 0.589 & 0.000 & 1.413 & 1.583 & 1.442 & 0.000 & 0.000 & 0.052 \\
\hline $\mathrm{DMU}_{8}$ & 12.37 & 0.452 & 0.000 & 0.000 & 0.000 & 0.000 & 0.000 & 0.000 & 0.000 \\
\hline $\mathrm{DMU}_{9}$ & 0.000 & 0.000 & 0.000 & 0.194 & 0.000 & 0.208 & 0.000 & 0.650 & 0.220 \\
\hline $\mathrm{DMU}_{10}$ & 6.858 & 0.312 & 0.000 & 1.351 & 0.000 & 0.000 & 0.724 & 0.000 & 0.571 \\
\hline $\mathrm{DMU}_{11}$ & 0.801 & 0.132 & 0.000 & 0.000 & 0.000 & 0.000 & 0.000 & 0.000 & 0.000 \\
\hline $\mathrm{DMU}_{12}$ & 0.000 & 0.000 & 0.000 & 0.000 & 0.000 & 0.000 & 0.000 & 0.000 & 0.000 \\
\hline $\mathrm{DMU}_{13}$ & 0.000 & 0.000 & 0.000 & 0.000 & 0.000 & 0.000 & 0.000 & 0.000 & 0.000 \\
\hline $\mathrm{DMU}_{14}$ & 13.73 & 0.000 & 0.794 & 0.000 & 0.223 & 0.855 & 0.970 & 0.627 & 0.663 \\
\hline $\mathrm{DMU}_{15}$ & 27.18 & 0.027 & 0.000 & 1.663 & 0.496 & 0.000 & 0.852 & 0.000 & 1.530 \\
\hline $\mathrm{DMU}_{16}$ & 0.000 & 0.000 & 0.000 & 0.000 & 0.000 & 0.000 & 0.000 & 0.000 & 0.000 \\
\hline $\mathrm{DMU}_{17}$ & 6.349 & 0.537 & 0.000 & 2.641 & 0.000 & 0.664 & 0.000 & 0.000 & 1.498 \\
\hline $\mathrm{DMU}_{18}$ & 0.000 & 0.000 & 0.000 & 0.000 & 0.000 & 0.000 & 0.000 & 0.000 & 0.000 \\
\hline $\mathrm{DMU}_{19}$ & 5.383 & 0.106 & 0.000 & 0.808 & 0.540 & 0.415 & 0.000 & 0.000 & 0.345 \\
\hline $\mathrm{DMU}_{20}$ & 0.000 & 0.026 & 0.000 & 0.639 & 2.670 & 0.000 & 1.351 & 0.000 & 1.952 \\
\hline $\mathrm{DMU}_{21}$ & 23.29 & 0.171 & 0.000 & 0.000 & 0.000 & 0.000 & 0.000 & 0.000 & 0.000 \\
\hline $\mathrm{DMU}_{22}$ & 0.000 & 0.000 & 0.000 & 0.000 & 0.000 & 0.000 & 0.000 & 0.000 & 0.000 \\
\hline $\mathrm{DMU}_{23}$ & 0.000 & 0.000 & 0.784 & 2.507 & 3.486 & 0.301 & 0.000 & 0.591 & 0.362 \\
\hline $\mathrm{DMU}_{24}$ & 1.840 & 0.000 & 2.012 & 0.133 & 1.457 & 1.040 & 0.000 & 0.124 & 0.873 \\
\hline $\mathrm{DMU}_{25}$ & 0.000 & 0.000 & 0.000 & 0.000 & 0.000 & 0.000 & 0.000 & 0.000 & 0.000 \\
\hline $\mathrm{DMU}_{26}$ & 0.000 & 0.000 & 0.000 & 0.000 & 0.000 & 0.000 & 0.000 & 0.000 & 0.000 \\
\hline $\mathrm{DMU}_{27}$ & 0.000 & 0.000 & 0.000 & 0.000 & 0.000 & 0.000 & 0.000 & 0.000 & 0.000 \\
\hline $\mathrm{DMU}_{28}$ & 0.000 & 0.116 & 0.000 & 0.000 & 0.000 & 0.000 & 0.000 & 0.000 & 0.000 \\
\hline Average & 4.595 & 0.121 & 0.128 & 0.554 & 0.396 & 0.221 & 0.191 & 0.129 & 0.469 \\
\hline
\end{tabular}

Table 6: Efficient input and output target values for each DMU

\begin{tabular}{|c|c|c|c|c|c|c|c|c|c|}
\hline \multirow{2}{*}{ Unit } & \multicolumn{2}{|c|}{ Input } & \multicolumn{7}{|c|}{ Output } \\
\hline & $\widehat{x}_{1}$ & $\widehat{x}_{2}$ & $\widehat{y}_{1}$ & $\widehat{y}_{2}$ & $\widehat{y}_{3}$ & $\widehat{y}_{4}$ & $\widehat{y}_{5}$ & $\widehat{y}_{6}$ & $\widehat{y}_{7}$ \\
\hline $\mathrm{DMU}_{1}$ & 32.61 & 0.38 & 9.57 & 10.00 & 6.50 & 8.00 & 8.60 & 9.33 & 9.45 \\
\hline $\mathrm{DMU}_{2}$ & 9.89 & 0.24 & 9.57 & 8.89 & 9.59 & 9.34 & 8.40 & 8.54 & 8.89 \\
\hline $\mathrm{DMU}_{3}$ & 14.37 & 0.41 & 9.76 & 8.40 & 9.12 & 9.65 & 8.76 & 7.96 & 9.51 \\
\hline $\mathrm{DMU}_{4}$ & 38.51 & 0.96 & 8.75 & 7.45 & 7.73 & 8.87 & 9.30 & 7.90 & 7.90 \\
\hline $\mathrm{DMU}_{5}$ & 2.00 & 0.29 & 8.03 & 7.06 & 7.04 & 8.02 & 7.32 & 6.56 & 7.43 \\
\hline $\mathrm{DMU}_{6}$ & 14.17 & 0.39 & 9.38 & 8.90 & 8.89 & 9.41 & 8.63 & 8.70 & 9.37 \\
\hline $\mathrm{DMU}_{7}$ & 11.90 & 0.21 & 9.57 & 9.17 & 9.09 & 9.03 & 8.29 & 8.97 & 8.88 \\
\hline $\mathrm{DMU}_{8}$ & 10.80 & 0.44 & 8.78 & 9.12 & 9.46 & 9.65 & 8.68 & 8.95 & 9.19 \\
\hline
\end{tabular}


Table 6: Efficient input and output target values for each DMU

\begin{tabular}{|c|c|c|c|c|c|c|c|c|c|}
\hline \multirow{2}{*}{ Unit } & \multicolumn{2}{|c|}{ Input } & \multicolumn{7}{|c|}{ Output } \\
\hline & $\widehat{x}_{1}$ & $\widehat{x}_{2}$ & $\widehat{y}_{1}$ & $\widehat{y}_{2}$ & $\widehat{y}_{3}$ & $\widehat{y}_{4}$ & $\widehat{y}_{5}$ & $\widehat{y}_{6}$ & $\widehat{y}_{7}$ \\
\hline $\mathrm{DMU}_{9}$ & 7.04 & 0.32 & 9.20 & 8.92 & 9.29 & 9.57 & 8.40 & 9.32 & 9.25 \\
\hline $\mathrm{DMU}_{10}$ & 9.66 & 0.27 & 9.22 & 9.15 & 9.75 & 9.34 & 8.43 & 8.73 & 8.75 \\
\hline $\mathrm{DMU}_{11}$ & 7.39 & 0.14 & 9.62 & 9.05 & 9.79 & 9.17 & 8.18 & 8.79 & 8.60 \\
\hline $\mathrm{DMU}_{12}$ & 5.33 & 0.48 & 8.23 & 6.50 & 8.75 & 8.33 & 8.80 & 8.00 & 8.50 \\
\hline $\mathrm{DMU}_{13}$ & 16.04 & 0.08 & 8.80 & 8.04 & 8.30 & 8.59 & 8.60 & 7.84 & 8.40 \\
\hline $\mathrm{DMU}_{14}$ & 16.45 & 0.18 & 9.62 & 9.53 & 8.54 & 8.59 & 8.23 & 9.15 & 8.78 \\
\hline $\mathrm{DMU}_{15}$ & 11.78 & 0.44 & 8.92 & 9.00 & 9.42 & 9.65 & 9.72 & 8.74 & 9.24 \\
\hline $\mathrm{DMU}_{16}$ & 13.12 & 0.40 & 9.25 & 9.35 & 8.25 & 9.30 & 8.00 & 9.67 & 8.70 \\
\hline $\mathrm{DMU}_{17}$ & 19.61 & 0.41 & 9.34 & 9.21 & 8.34 & 9.08 & 8.69 & 8.76 & 9.38 \\
\hline $\mathrm{DMU}_{18}$ & 32.07 & 0.06 & 8.50 & 7.00 & 8.25 & 8.33 & 8.42 & 8.67 & 7.60 \\
\hline $\mathrm{DMU}_{19}$ & 19.50 & 0.45 & 8.83 & 9.69 & 8.33 & 9.03 & 8.55 & 9.26 & 9.00 \\
\hline $\mathrm{DMU}_{20}$ & 8.56 & 0.33 & 9.22 & 8.19 & 9.23 & 9.16 & 8.53 & 8.48 & 8.95 \\
\hline $\mathrm{DMU}_{21}$ & 10.11 & 0.41 & 8.93 & 9.04 & 9.40 & 9.63 & 8.62 & 8.99 & 9.22 \\
\hline $\mathrm{DMU}_{22}$ & 29.96 & 0.88 & 8.45 & 9.03 & 9.49 & 9.04 & 6.77 & 9.34 & 6.99 \\
\hline $\mathrm{DMU}_{23}$ & 4.83 & 0.09 & 9.41 & 8.84 & 9.62 & 8.87 & 7.96 & 8.73 & 8.24 \\
\hline $\mathrm{DMU}_{24}$ & 5.13 & 0.04 & 9.66 & 9.21 & 9.98 & 9.01 & 7.98 & 9.03 & 8.32 \\
\hline $\mathrm{DMU}_{25}$ & 7.13 & 0.45 & 6.98 & 8.74 & 9.37 & 7.55 & 7.98 & 9.74 & 7.99 \\
\hline $\mathrm{DMU}_{26}$ & 15.07 & 0.64 & 7.62 & 9.80 & 9.91 & 9.77 & 9.10 & 8.86 & 8.94 \\
\hline $\mathrm{DMU}_{27}$ & 19.08 & 0.83 & 9.82 & 7.24 & 7.32 & 7.72 & 7.76 & 7.79 & 9.28 \\
\hline $\mathrm{DMU}_{28}$ & 5.13 & 0.04 & 9.66 & 9.21 & 9.98 & 9.01 & 7.98 & 9.03 & 8.32 \\
\hline Average & 14.19 & 0.37 & 9.02 & 8.70 & 8.88 & 8.95 & 8.38 & 8.71 & 8.68 \\
\hline
\end{tabular}

\subsection{Sensitivity Analysis}

In this step, the effect of macro-ergonomics and ergonomics criteria in the medicine SCM system is demonstrated, separately. In this regard, sensitivity analysis is applied. By using this analysis the influential KIPs are recognized that can help decision makers to propose the proper strategies by focusing on influential KIPs. In addition, the results of sensitivity analysis can demonstrate the role of each KIP in performance improvement and overcome to system complexity. Moreover, this analysis can be useful in complex systems such as hospital to enhance performance with respect to important KIPs. To do this, DEA model has been run 2 times with ergonomics and macro-ergonomics outputs separately. Technical efficiency by considering ergonomics factors, without considering macro-ergonomics, for each DMU is shown Table 7. 
Table 7: Technical efficiency of DMUs by considering ergonomics factors

\begin{tabular}{cccc}
\hline DMU & Technical efficiency & DMU & Technical efficiency \\
\hline $\mathrm{DMU}_{1}$ & 1 & $\mathrm{DMU}_{15}$ & 0.951 \\
$\mathrm{DMU}_{2}$ & 0.898 & $\mathrm{DMU}_{16}$ & 1 \\
$\mathrm{DMU}_{3}$ & 1 & $\mathrm{DMU}_{17}$ & 0.962 \\
$\mathrm{DMU}_{4}$ & 1 & $\mathrm{DMU}_{18}$ & 1 \\
$\mathrm{DMU}_{5}$ & 1 & $\mathrm{DMU}_{19}$ & 0.94 \\
$\mathrm{DMU}_{6}$ & 0.897 & $\mathrm{DMU}_{20}$ & 0.954 \\
$\mathrm{DMU}_{7}$ & 0.937 & $\mathrm{DMU}_{21}$ & 0.927 \\
$\mathrm{DMU}_{8}$ & 0.962 & $\mathrm{DMU}_{22}$ & 1 \\
$\mathrm{DMU}_{9}$ & 1 & $\mathrm{DMU}_{23}$ & 0.984 \\
$\mathrm{DMU}_{10}$ & 0.932 & $\mathrm{DMU}_{24}$ & 0.994 \\
$\mathrm{DMU}_{11}$ & 0.899 & $\mathrm{DMU}_{25}$ & 1 \\
$\mathrm{DMU}_{12}$ & 1 & $\mathrm{DMU}_{26}$ & 1 \\
$\mathrm{DMU}_{13}$ & 1 & $\mathrm{DMU}_{27}$ & 0.976 \\
$\mathrm{DMU}_{14}$ & 0.92 & $\mathrm{DMU}_{28}$ & 1 \\
\hline
\end{tabular}

In this step, ergonomics factors are only considered as outputs and DEA model run by considering 2 inputs and 2 outputs. The calculated value of efficiencies is shown in Table 7 and the average value of technical efficiencies by DEA model by considering ergonomics factors is 0.969 .

Technical efficiency by considering macro-ergonomics factors, without considering ergonomics factors, for each DMU is shown Table 8.

Table 8: Technical efficiency of DMUs by considering macro-ergonomics factors

\begin{tabular}{lclc}
\hline $\mathbf{D M U}_{\mathbf{j}}$ & Technical efficiency & $\mathbf{D M U}_{\mathbf{j}}$ & Technical efficiency \\
\hline $\mathrm{DMU}_{1}$ & 1 & $\mathrm{DMU}_{15}$ & 0.87 \\
$\mathrm{DMU}_{2}$ & 0.913 & $\mathrm{DMU}_{16}$ & 0.986 \\
$\mathrm{DMU}_{3}$ & 1 & $\mathrm{DMU}_{17}$ & 0.942 \\
$\mathrm{DMU}_{4}$ & 0.896 & $\mathrm{DMU}_{18}$ & 0.879 \\
$\mathrm{DMU}_{5}$ & 1 & $\mathrm{DMU}_{19}$ & 0.973 \\
$\mathrm{DMU}_{6}$ & 0.893 & $\mathrm{DMU}_{20}$ & 0.917 \\
$\mathrm{DMU}_{7}$ & 0.95 & $\mathrm{DMU}_{21}$ & 0.861 \\
$\mathrm{DMU}_{8}$ & 0.866 & $\mathrm{DMU}_{22}$ & 0.906 \\
$\mathrm{DMU}_{9}$ & 0.961 & $\mathrm{DMU}_{23}$ & 0.893 \\
$\mathrm{DMU}_{10}$ & 0.907 & $\mathrm{DMU}_{24}$ & 0.979 \\
$\mathrm{DMU}_{11}$ & 0.903 & $\mathrm{DMU}_{25}$ & 0.937 \\
$\mathrm{DMU}_{12}$ & 0.852 & $\mathrm{DMU}_{26}$ & 1 \\
$\mathrm{DMU}_{13}$ & 0.91 & $\mathrm{DMU}_{27}$ & 1 \\
$\mathrm{DMU}_{14}$ & 0.991 & $\mathrm{DMU}_{28}$ & 1 \\
\hline
\end{tabular}


In this step, the macro-ergonomics factors are only took into account as outputs and DEA model run by considering 2 inputs and 5 outputs. The average value of calculated efficiencies by using DEA model is 0.935 . Figure 4 shows the average technical efficiency with respect to macro-ergonomics and ergonomics criteria separately.

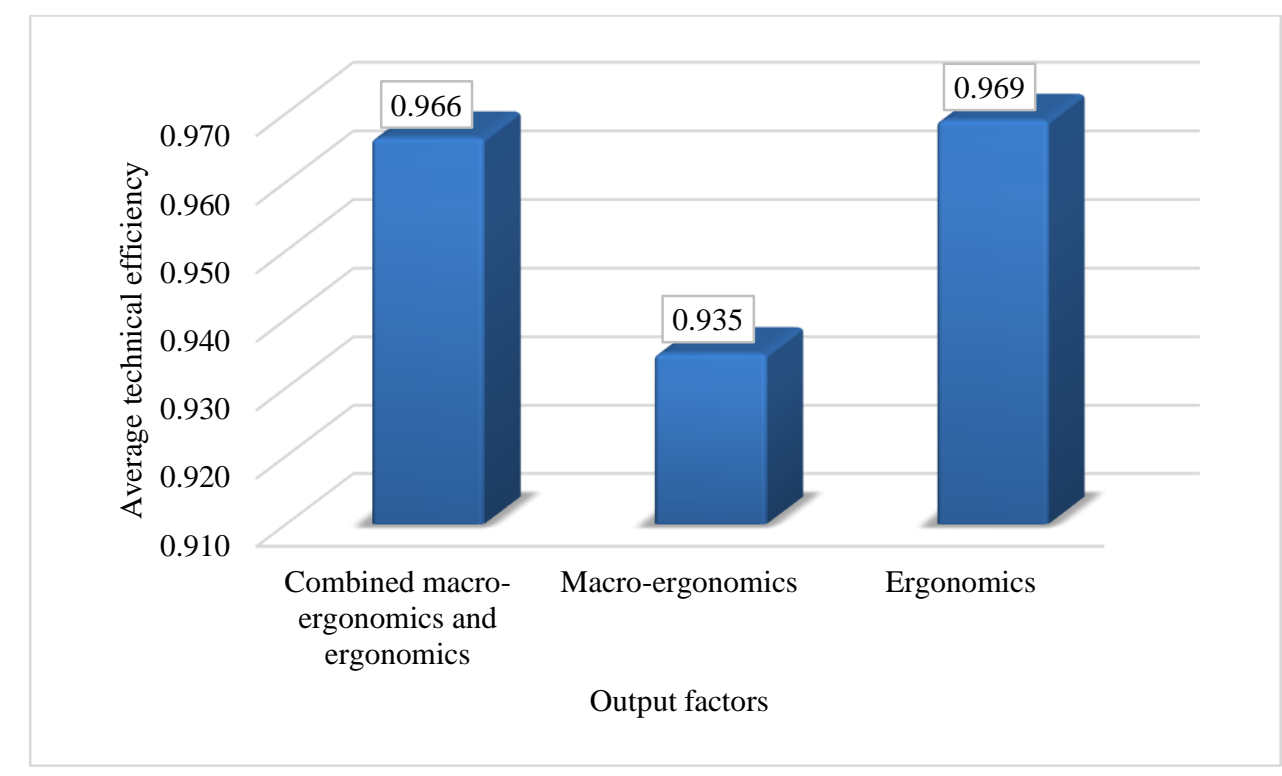

Figure 4. Sensitivity analysis results

According to the results in pervious steps and as seen in Figure 4, macro-ergonomics factors are more effective than ergonomics factors in reducing average efficiencies of DMUs. Therefore, macro-ergonomics factors have the greatest effect on efficiency scores. This category can play a key role in management decisions. It is therefore quite essential to identify the important macro-ergonomics indicators for continuous performance improvement. To recognize the most effective macro-ergonomics factor on efficiencies value, DEA model has been run 5 times for each macro-ergonomics factor, separately and the average value of efficiencies is calculated for all DMUs. Results are shown in Table 9. Figure 5 illustrates the percentage of change in the efficiency scores created by omitting each indicator. 
Table 9: Technical efficiency of DMUs by considering macro ergonomic factors

\begin{tabular}{|c|c|c|c|c|c|c|}
\hline \multirow[b]{2}{*}{$\begin{array}{l}\text { Macro- } \\
\text { ergonomics } \\
\text { factor }\end{array}$} & \multicolumn{5}{|c|}{ Omitted indicator } & \multirow[b]{2}{*}{$\begin{array}{l}\text { Considering } \\
\text { all macro- } \\
\text { ergonomics } \\
\text { indicator }\end{array}$} \\
\hline & $\begin{array}{l}\text { Knowledge } \\
\text { about } \\
\text { situation } \\
\text { assessment } \\
\text { and situation } \\
\text { analysis } \\
\end{array}$ & $\begin{array}{c}\text { Business } \\
\text { specifications } \\
\text { and } \\
\text { equipment }\end{array}$ & $\begin{array}{l}\text { Information } \\
\text { and } \\
\text { communication } \\
\text { in system }\end{array}$ & $\begin{array}{c}\text { Human } \\
\text { resource } \\
\text { management } \\
\text { culture }\end{array}$ & $\begin{array}{l}\text { Teamwork and } \\
\text { effective } \\
\text { communication }\end{array}$ & \\
\hline $\begin{array}{l}\text { Average value } \\
\text { of efficiencies }\end{array}$ & 0.947 & 0.942 & 0.910 & 0.929 & 0.908 & 0.935 \\
\hline
\end{tabular}

As seen in Table 9 and Figure 5, "teamwork and effective communication" and "information and communication in system" have the least average value of efficiencies in this SCM system and must be improved by decision makers.

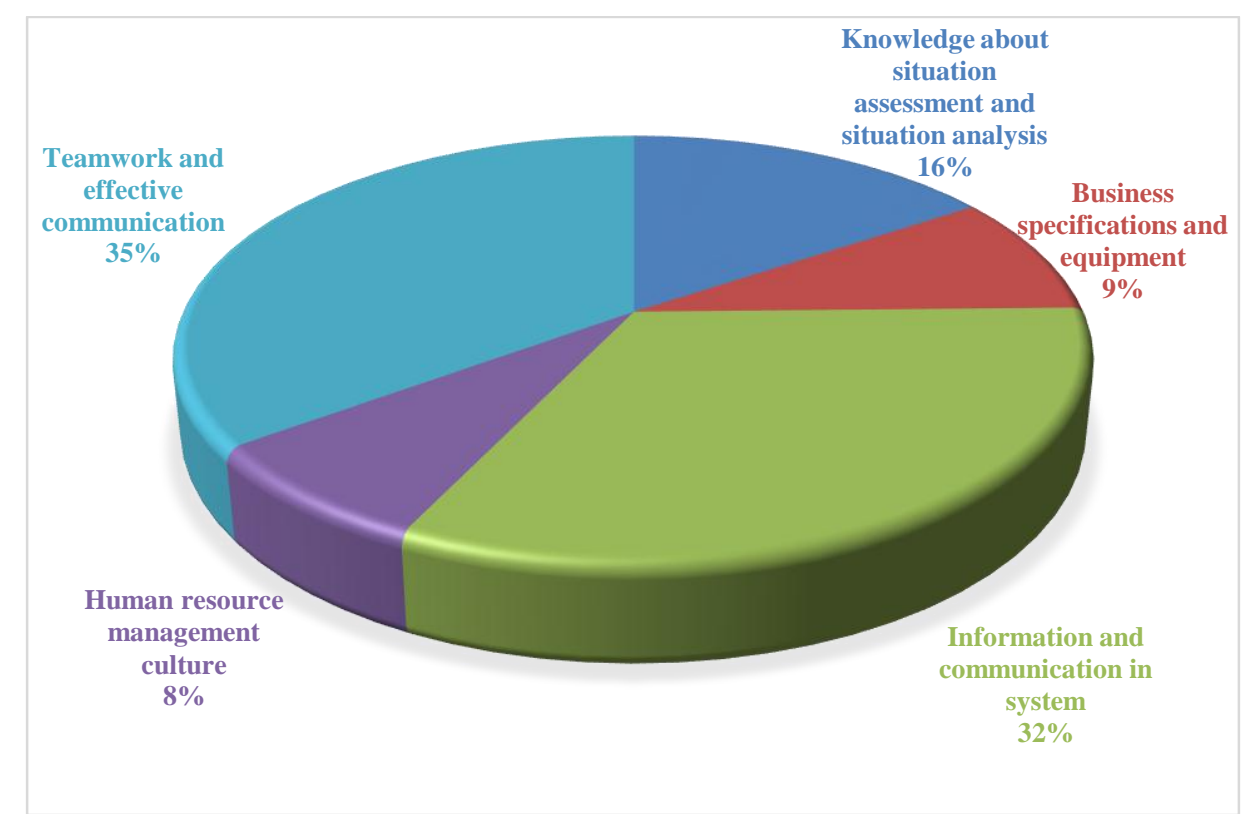

Figure 5: The importance of each macro-ergonomics indicator in this particular case study

\section{Management Decisions and Discussion}

In this section management decisions are described based on performance of medicine SC for this study. According to computed efficiencies, efficient and inefficient sections are identified. As seen in Table 4, Marketing-02, Technical-01, and Finance-01 have the highest efficiency in this case study; this means that the aforementioned sectors have the best 
performance with respect to human factors namely ergonomics and macro-ergonomics. Figure 6 illustrates the associated efficiency for each sector.

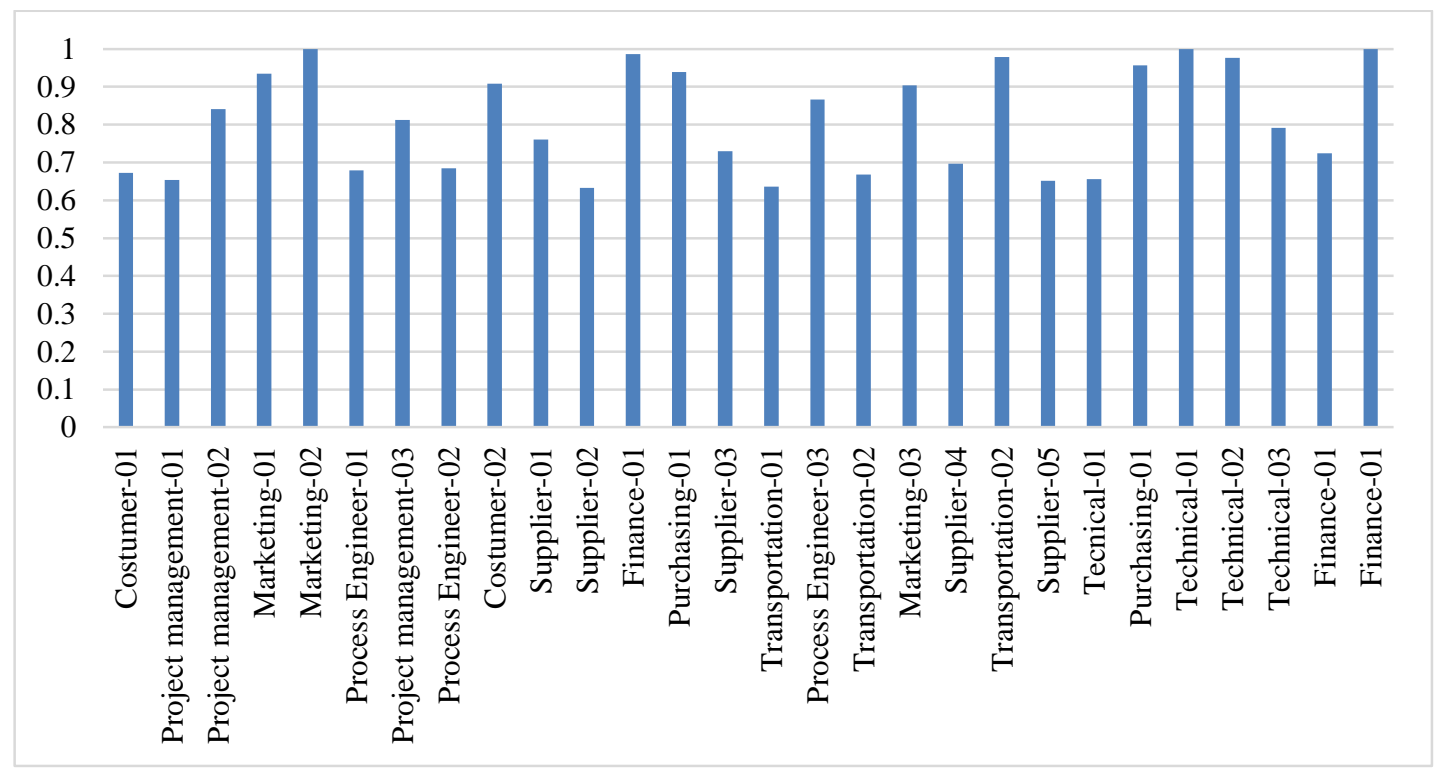

Figure 6: Average efficiency for each sector of medicine SC

Moreover, the results of sensitivity analysis demonstrates the effect of macro-ergonomics factors on reducing system's efficiency. In each SC system, information is crucial to prevent unexpected events. Also, transfer of information would be important in system, especially by human. Imperfect or excluded information in SCM system causes problems and delays (Siemieniuch and Sinclair, 2000). Transfer of information in SCM system would be possible by an effective communication. Also, communication in system can be defined as connection between people and the way of transferring information in system. Problems in communication of system can cause reduction of efficiency. People perform related tasks when they are in a group and have interaction with each other dynamically. Teamwork is defined as those behaviors that facilitate effective interaction of these people (Beaubien and Baker, 2004).

According to Table 9 and Figure 5, the most problem is about teamwork and communication in the SCM system under study. Also, "Knowledge of staff and the ability of situation assessment and analysis" and "Business specification and required equipment for job" 
is acceptable in this SCM system. It means that managers and staff have suitable knowledge for their job and they can assess and analyze different situation properly, but they have problems to communicate with each other and to transform information. It can be caused by different issues such as lack of suitable information technology facilities or lack of training policies for information transformation. In macro-ergonomics point of view, this issue is categorized as organizational related part (International Ergonomics Association, 2014).

SCM in this hospital requires a systematic approach or framework for educating and training workers in teamwork. Managers require planning, developing and implementation decisions based on the characteristics of business processes (Gunasekaran and Ngai, 2004). Communication issue in this hospital can be improved by changing in managerial policies and educating people.

To improve the medicine SCM system performance of this hospital, the target values measured by DEA method are been used. So, the average potential for improvement by using average efficient target values, based on Tables 2 and 6, can be achieved and the potential values for improvement of human factors for this particular hospital are shown in Table 10. Finally, it is completed by auditing and using improvement tools. Consequently by running this cycle different efficiencies values are calculated. Thus, managers can compare the value of efficiencies to perform proper improvements policies and find the weakness of system in human factors point of view.

Table 10: Potential values for improvement of human factors for this particular hospital

\begin{tabular}{lccccccc}
\hline & $y_{1}$ & $y_{2}$ & $y_{3}$ & $y_{4}$ & $y_{5}$ & $y_{6}$ & $y_{7}$ \\
\hline Target & 9.02 & 8.70 & 8.88 & 8.95 & 8.38 & 8.71 & 8.68 \\
Measured & 8.72 & 8.00 & 8.31 & 8.56 & 8.00 & 8.41 & 8.06 \\
$\begin{array}{l}\text { Potential Value for } \\
\text { improvement }\end{array}$ & 0.3 & 0.7 & 0.57 & 0.39 & 0.38 & 0.3 & 0.62 \\
\hline
\end{tabular}




\section{Conclusions}

Healthcare industry plays an important role in each society. Medicine SC is one of the most costly divisions of healthcare industry. Also, human effects in such systems are inevitable. This study presented an efficient approach for analyzing impact of macro-ergonomics factors on medicine SC of an actual hospital. To do this, DEA approach has been applied to recognize the influential factors. The proposed approach enables managers of hospital to propose developmental strategies for each division with respect to human factors issues. Moreover, this approach can indicate strengths and weaknesses of each division in medicine SCM. In addition, auditing and monitoring is applied to improve system performance. Moreover, this approach formulates improvement strategies for medicine SC system with respect to human factors issues and can ensure improvement for managers.

In this study, the term human factors actually are composed of conventional human factors, organizational factors and macro-ergonomics factors. For future studies, it is recommended to categorize the general format of this study into human factors, organizational features and macro-ergonomics factors. Also, certain parameters may have uncertain nature and therefore fuzzy DEA may be used in this perspective. Additionally, developing and applying novel methods and approaches in this matter is highly recommended.

Table 11 presents the features of the proposed methodology. This study presents the impact of macro-ergonomics factor on a healthcare SC through DEA model. It also is capable of presenting improvement in medicine SC system in healthcare industry. Furthermore it is capable of modeling macro-ergonomics and organizational factors in addition to human related factors. It also helps managers to identify errors and weaknesses in their system and provides solutions to optimize system performance. 
Table 11: The features of proposed methodology versus other studies

\begin{tabular}{ccccc}
\hline & \multicolumn{3}{c}{ Feature } \\
\cline { 2 - 5 } Study & $\begin{array}{c}\text { Healthcare industry } \\
\text { assessment }\end{array}$ & $\begin{array}{c}\text { Modeling macro- } \\
\text { ergonomics and } \\
\text { organizational } \\
\text { Factors }\end{array}$ & $\begin{array}{c}\text { Modeling } \\
\text { human related } \\
\text { factors }\end{array}$ & $\begin{array}{c}\text { Qualitative } \\
\text { parameters }\end{array}$ \\
Optimization \\
\hline The frame work of this study & $\checkmark$ & $\checkmark$ & $\checkmark$ & $\checkmark$ \\
Siemieniuch et al. (2000) & $\checkmark$ & & $\checkmark$ & $\checkmark$ \\
Bendavid et al. (2011) & $\checkmark$ & $\checkmark$ & $\checkmark$ & $\checkmark$ \\
McKone-Sweet et al. (2005) & $\checkmark$ & $\checkmark$ & $\checkmark$ & $\checkmark$ \\
Azadeh et al. (2012) & & & $\checkmark$ \\
Kim (2005) & $\checkmark$ & & $\checkmark$ \\
Khan et al. (2013) & $\checkmark$ & & $\checkmark$ \\
\hline
\end{tabular}

\section{Acknowledgment}

The authors are grateful for the valuable comments and suggestions from the respected reviewers. Their valuable comments and suggestions have enhanced the strength and significance of our paper.

\section{References}

Azadeh, A. (2007). Auto Assess Software and Manual, School of Industrial Engineering, University of Tehran, Iran.

Azadeh, A., Asadzadeh, S. M., Bukhari, A., \& Izadbakhsh, H. R. (2011). An integrated fuzzy DEA algorithm for efficiency assessment and optimization of wireless communication sectors with ambiguous data. The International Journal of Advanced Manufacturing Technology, 52(5-8), 805-819.

Azadeh, A., Farmand, A. H., \& Sharahi, Z. J. (2012). Performance assessment and optimization of HSE management systems with human error and ambiguity by an integrated fuzzy multivariate approach in a large conventional power plant manufacturer. Journal of Loss Prevention in the Process Industries, 25(3), 594-603.

Azadeh, A., Gaeini, Z., \& Moradi, B. (2014). Optimization of HSE in maintenance activities by integration of continuous improvement cycle and fuzzy multivariate approach: A gas refinery. Journal of Loss Prevention in the Process Industries, 32, 415-427. 
Azadeh, A., Sepahi, M., \& Haghighi, S. M. (2013). An integrated simulation-DEA approach to improve quality care of medical centres. International Journal of Process Management and Benchmarking, 3(3), 352-370.

Azadeh, A., Tohidi, H., Zarrin, M., Pashapour, S., \& Moghaddam, M. (2016). An integrated algorithm for performance optimization of neurosurgical ICUs. Expert Systems with Applications, 43, 142-153.

Banker, R.D., Charnes, R. F., Cooper, W. W. (1984). Some models for estimating technical and scale inefficiencies in data envelopment analysis. Management Science, 30, 10781092.

Barnes, J., \& Liao, Y. (2012). The effect of individual, network, and collaborative competencies on the supply chain management system. International Journal of Production Economics, 140(2), 888-899.

Beaubien, J. M., \& Baker, D. P. (2004). The use of simulation for training teamwork skills in health care: how low can you go?. Quality and safety in health care, 13(suppl 1), i51i56.

Behzad, B., Moraga, R. J., \& Chen, S. J. G. (2011). Modelling healthcare internal service supply chains for the analysis of medication delivery errors and amplification effects. Journal of Industrial Engineering and Management, 4(4), 554-576.

Bendavid, Y., \& Boeck, H. (2011). Using RFID to improve hospital supply chain management for high value and consignment items. Procedia Computer Science, 5, 849-856.

Bozarth, C. C., Warsing, D. P., Flynn, B. B., \& Flynn, E. J. (2009). The impact of supply chain complexity on manufacturing plant performance. Journal of Operations Management, 27(1), 78-93.

Carayon, P. (2006). Human factors of complex sociotechnical systems. Applied ergonomics, $37(4), 525-535$. 
Chaffin D.B., Andersson G., Martin B.J. (2006).Occupational Biomechanics text book.

Chan, H. K. (2011). Supply chain systems-Recent trend in research and applications. Systems Journal, IEEE, 5(1), 2-5.

Chan, H. K., \& Chan, F. T. (2010). Comparative study of adaptability and flexibility in distributed manufacturing supply chains. Decision Support Systems, 48(2), 331-341.

Charnes, A., Cooper, W. W., \& Rhodes, E. (1978). Measuring the efficiency of decision making units. European journal of operational research, 2(6), 429-444.

Clegg, C. W. (2000). Sociotechnical principles for system design. Applied ergonomics, 31(5), 463-477.

Davis, L.E. (1982). Organizational design. In G. Salvendy (Ed.), Handbook of human factors (pp. 433-452). New York: John Wiley \& Sons.

Fung, P. K., \& Chen, I. S. (2010). Human capital for supply chain management capabilities: a study of international trade intermediaries. International Journal of Logistics: Research and Applications, 13(1), 1-12.

Gunasekaran, A., \& Ngai, E. W. (2004). Information systems in supply chain integration and management. European Journal of Operational Research, 159(2), 269-295.

HARRISON, A. (1999). Horses for courses: human aspects of different logistics systems. International Journal of Logistics: Research and Applications, 2(3), 247-261.

Jacobs, R. (2001). Alternative methods to examine hospital efficiency: data envelopment analysis and stochastic frontier analysis. Healthcare Management Science, 4(2), 103 115.

Jahanshahloo, G. R., Memariani, A., Lotfi, F. H., \& Rezai, H. Z. (2005). A note on some of DEA models and finding efficiency and complete ranking using common set of weights. Applied Mathematics and Computation, 166(2), 265-281. 
Kehrel, U. (2014). The acceptance of process innovations in drug supply-An empirical analysis of patient-individualized blister packaging in stationary nursing facilities. International Journal of Healthcare Management.

Kelle, P., Woosley, J., \& Schneider, H. (2012). Pharmaceutical supply chain specifics and inventory solutions for a hospital case. Operations Research for Health Care, 1(2), 5463.

Khan, M., Jaber, M. Y., \& Ahmad, A. R. (2014). An integrated supply chain model with errors in quality inspection and learning in production. Omega, 42(1), 16-24.

Kim, B., Elstein, Y., Shiner, B., Konrad, R., Pomerantz, A. S., \& Watts, B. V. (2013). Use of discrete event simulation to improve a mental health clinic. General hospital psychiatry, 35(6), 668-670.

Kim, D. (2005). An integrated supply chain management system: a case study in healthcare sector. In E-Commerce and Web Technologies (pp. 218-227). Springer Berlin Heidelberg.

Konrad, R., DeSotto, K., Grocela, A., McAuley, P., Wang, J., Lyons, J., \& Bruin, M. (2013). Modeling the impact of changing patient flow processes in an emergency department: Insights from a computer simulation study. Operations Research for Health Care, 2(4), $66-74$.

Koudal, P., and Engel, D. A. (2007). Globalization and emerging markets the challenge of continuous global network optimization. International Series in Operations Research \& Management Science, 98, 98, 37-66.

Koulikoff-Souviron, M., \& Harrison, A. (2006). Buyer-supplier relationships in inter-and intra-organisational supply contexts: the unobtrusive yet pervasive human resource picture. International Journal of Logistics: Research and Applications, 9(1), 75-94. 
Lovell, C. A. K., \& Rouse, A. P. B. (2003). Equivalent standard DEA models to provide superefficiency scores. Journal of the Operational Research Society, 54(1), 101-108.

Lowndes, B.R., and Susan, M. (2014). Overview of Human Factors and Ergonomics in the OR, with an Emphasis on Minimally Invasive Surgeries. Human Factors and Ergonomics in Manufacturing \& Service Industries, 24(3), pp. 308-317.

McGrath, G. M., \& More, E. (2001, January). Data integration along the healthcare supply chain: The pharmaceutical extranet gateway project. In System Sciences, 2001. Proceedings of the 34th Annual Hawaii International Conference on (pp. 8-pp). IEEE.

McKone-Sweet, K. E., Hamilton, P., \& Willis, S. B. (2005). The ailing healthcare supply chain: a prescription for change. Journal of Supply Chain Management, 41(1), 4-17.

MHaszlinna Mustaffa, N., \& Potter, A. (2009). Healthcare supply chain management in Malaysia: a case study. Supply Chain Management: An International Journal, 14(3), 234-243.

Narayana, S. A., Pati, R. K., \& Vrat, P. (2014). Managerial research on the pharmaceutical supply chain-A critical review and some insights for future directions. Journal of Purchasing and Supply Management, 20(1), 18-40.

Paillé, P., \& Boiral, O. (2013). Pro-environmental behavior at work: Construct validity and determinants. Journal of Environmental Psychology, 36, 118-128.

Parkin, D., \& Hollingsworth, B. (1997). Measuring production efficiency of acute hospitals in Scotland, 1991-94: validity issues in data envelopment analysis. Applied Economics, 29(11), 1425-1433.

Perona, M., \& Miragliotta, G. (2004). Complexity management and supply chain performance assessment. A field study and a conceptual framework. International journal of production economics, 90(1), 103-115.

Rossetti, M. D. (2008). Inventory manage issue in healthcare supply chains. 
Salinas-Jiménez, J., \& Smith, P. (1996). Data envelopment analysis applied to quality in primary health care. Annals of Operations Research, 67(1), 141-161.

Serdarasan, S. (2013). A review of supply chain complexity drivers. Computers \& Industrial Engineering.

Siemieniuch, C. E., \& Sinclair, M. A. (2000). Implications of the supply chain for role definitions in concurrent engineering. Human Factors and Ergonomics in Manufacturing \& Service Industries, 10(3), 251-272.

Sinclair, M. A., Siemieniuch, C. E., Cooper, K. A., \& Waddell, N. (1995). A discussion of simultaneous engineering and the manufacturing supply chain, from an ergonomics perspective. International Journal of Industrial Ergonomics, 16(4), 263-281.

Sueyoshi, T. (1999). DEA-discriminant analysis in the view of goal programming. European Journal of Operational Research, 115(3), 564-582.

Ulich, E. (1989). Humanization of work-concepts and cases. In B.J. Fallon, H.P. Fister, \& J. Brebner (Eds.), Advances in industrial organizational psychology (pp. 133-143). Amsterdam: Elsevier.

Vachon, S., \& Klassen, R. D. (2002). An exploratory investigation of the effects of supply chain complexity on delivery performance. Engineering Management, IEEE Transactions on, 49(3), 218-230.

Van der Vorst, J. G., \& Beulens, A. J. (2002). Identifying sources of uncertainty to generate supply chain redesign strategies. International Journal of Physical Distribution \& Logistics Management, 32(6), 409-430.

Wang, C. H., \& Chou, H. L. (2014). Assessment of Patient Safety Management from Human Factors Perspective: A Fuzzy TOPSIS Approach. Human Factors and Ergonomics in Manufacturing \& Service Industries. In press. 
Wu, D. D., \& Olson, D. (2010). Enterprise risk management: a DEA VaR approach in vendor selection. International Journal of Production Research, 48(16), 4919-4932.

\section{Appendix I: Questionnaire}

1- Mental power

1-1- Do you have emotional stability and patience in working conditions?

1-2- Do you have focus, vigilance and good memory to work?

1-3- Do you have responsibility and interest to work?

1-4- Are you flexible in work?

1-5- Can you have a speed of decision-making on various issues?

2- Physical conditions

2-1- Do you feel fatigued at work?

2-2- Do you attend to physical health at work?

2-3- Is the pollution effected on the body?

3- Knowledge, situation assessment and situation analysis

3-1- Do you have enough knowledge and understanding of work?

3-2- Do you have reasonable judgment at various condition?

3-3- Do you have enough power and skill in managing work stress?

3-4- Do you have enough experience and learning potential?

4- Specifications of work and equipment

4-1- $\quad$ Are the tools designed ergonomic?

4-2- Is there up-to-date and correct operation of available electronic devices?

4-3- Are there clarity, readability and usability of work procedures?

5- Information and communication system

5-1- $\quad$ Are required information transferred with high precision and speed?

5-2- Is there the updating the network information system?

5-3- Is the common language used to communicate?

5-4- Are there the fast and convenient access to the required data?

6- Human resource management and work culture

6-1- Do you select the skilled staff and assign them important tasks and get feedback from them to improve work?

6-2- $\quad$ Are there the division of labor, adequate number of staff?

6-3- Are there principle courses even for experts?

6-4- Do you use up-to-date standards and provide necessary recourses?

6-5- Do you establish common goals and satisfy the professional and personal basic needs?

6-6- Are there the accurate documentation, recording faults for analyzing and preventing from repetition in future?

7- Teamwork and effective communication

7-1- Are there proper division of work and responsibilities to experts, skilled and experienced person who has been trained?

7-2- Are there effective communication, effective communication channels and work information, unfinished works, and temporary conditions are easily exchangeable in shifts? 